\title{
Ensenyar i aprendre coneixements gramaticals al voltant de la frase: Una experiència a cicle inicial
}

\author{
Anna Méndez i Navarro \\ Universitat Autònoma de Barcelona, Barcelona, Espanya
}

(Article rebut el 20 de març de 2012; versió final rebuda el 10 de maig de 2012)

\begin{abstract}
Amb l'objectiu de donar suport als centres en el tractament de les llengües en el context de l'actual diversitat lingüística i cultural, el Departament d'Ensenyament promou des del curs 2007-2008 el nou Projecte d'actualització de la metodologia d'Immersió Lingüística. El projecte consisteix bàsicament en facilitar a les escoles integrants els recursos formatius necessaris per assolir amb èxit aquest repte. Una de les activitats de les diverses accions formatives es complementa amb unes sessions de modelització en què formadores del Departament exemplifiquen com desenvolupar a les aules les estratègies i els continguts abordats en la formació. En aquest context el present article es proposa analitzar una de les sessions de modelització sobre l'ensenyament de coneixements al voltant de la frase al Cicle Inicial. Una anàlisi que permet destacar algunes qüestions a optimitzar en aquestes sessions.
\end{abstract}

A Vicenç Casalta, in memoriam

\section{Introducció}

El Servei d'Immersió i Ús de la Llengua del Departament d'Ensenyament (l'actual Servei d'Immersió i Acolliment Lingüístics, SIAL) posa en marxa el 2007 el nou Projecte d'actualització de la metodologia d'Immersió Lingüística (a partir d'ara, PIL). Un projecte que, d'acord amb el previst, finalitza el proper 2013.

Amb l'objectiu de donar suport als centres educatius en la consolidació de la llengua catalana com a eix vertebrador d'un projecte plurilingüe, el PIL es desenvolupa entorn dos grans eixos d'actuació: 1) l'actualització de la formació del professorat i 2) la incentivació de l'edició de materials i la difusió de bones pràctiques. En relació al primer dels eixos d'actuació, durant la fase inicial del projecte, el professorat de les escoles integrants del PIL participa en un seminari dirigit especialment a docents d'Educació Infantil i Cicle Inicial i impartit per formadors/es experts en immersió del SIAL. Aquesta activitat es complementa amb dues o tres modelitzacions a les aules per part del formador/a del SIAL, amb la 
finalitat d'exemplificar com portar a terme amb l'alumnat les estratègies i els continguts treballats al seminari formatiu. En aquest context, el present article es proposa analitzar una de les sessions de modelització de reflexió metalingüística dins del treball de la frase ${ }^{1}$ que portà a terme una formadora del SIAL en un centre del Vallès Occidental.

L'anàlisi d'aquesta sessió permet observar algunes qüestions a optimitzar en les sessions de modelització del PIL. Per fer-ho, el treball es desenvolupa al voltant de cinc punts bàsics. En l'apartat dels referents teòrics, es descriuen breument els plantejaments teòrics en què se sustenta la recerca. A continuació es presenta la metodologia de la investigació. Tot seguit, a l'escola i la sessió de modelització del PIL, es descriu el centre on té lloc la sessió observada i es relacionen els objectius, els continguts i les principals activitats d'aprenentatge desenvolupades, d'acord amb la planificació de la sessió. Després es passa a la descripció i anàlisi de la sessió de modelització a partir de dos eixos d'anàlisi, essent el primer, els conceptes de gramàtica pedagògica i d'oració que té en la seva base i, el segon, els coneixements que es construeixen a partir de la reflexió durant la seqüència instruccional, d'acord amb aquests conceptes. Per acabar, i després de la identificació i discussió dels punts febles en base a aquests dos eixos d'anàlisi, es fa una proposta per optimitzar les sessions de modelització del PIL en relació a la reflexió sobre la llengua dins del treball de la frase 2.

\section{Referents teòrics}

El marc teòric que fonamenta la recerca es relaciona $\mathrm{amb}$ els següents àmbits d'estudi: a) l'activitat de reflexió sobre la llengua i b) la gramàtica pedagògica i el tractament de l'oració. L'activitat reflexiva sobre la llengua fa referència al coneixement sobre la llengua i a la manifestació d'aquest coneixement. Des de diferents perspectives teòriques s'ha posat de relleu, per una banda, la capacitat de la llengua per a referir-se a si mateixa $i$, per una altra, la capacitat dels parlants per controlar la producció i recepció lingüístico-discursiva, i la seva capacitat de mostrar un coneixement més o menys explícit sobre la llengua i el seu ús (Camps i Milian, 2000; Camps, Guasch, Milian, i Ribas, 2005).

Des del punt de vista de la psicologia sociocultural, des del qual se situa la present recerca, el desenvolupament de les formes de pensament no pot ser entès 
sense tenir en compte la naturalesa intrínsecament social i comunicativa de la vida humana. Així, de la mateixa manera que el coneixement sobre el món sorgeix de l'activitat compartida, el coneixement sobre la llengua es genera també en la relació interpersonal per a interioritzar-se després i esdevenir coneixement individual. El llenguatge no és un objecte aïllat, que s'ofereix per observar-lo i analitzar-lo, sinó que forma part del bagatge intel·lectual i el desenvolupament psicològic dels individus a partir de l'ús, de la relació amb els altres (Camps, et al., 2005).

Posat que el coneixement que tenim sobre la llengua està lligat a l'ús, des d'aquest enfocament, que té les seves arrels en els treballs de Vygotsky (1978), l'activitat de reflexió sobre la llengua fa referència a la consideració de la llengua o la manera d'usar-la en funció de la intenció que és subjacent a aquest ús com a objecte de pensament (Camps, et al., 2005). D'aquesta manera, l'activitat metalingüística que tots els individus exercim es desencadena a partir de les situacions d'ús i es manifesta en el control de l'ús competent de la llengua.

Pel que fa a la gramàtica pedagògica i el tractament de l'oració, no hi ha dubte que en la selecció dels aspectes gramaticals de les diverses gramàtiques que formen part d'un currículum concret, és determinant la concepció que rau en la seva base del què és saber i aprendre llengua, i el valor atribuït al coneixement del sistema lingüístic, seguint Camps et al. (2005). En el nostre cas, les noves ordenacions curriculars (Decrets 142 i 143/2007), a diferència de les anteriors de 1992, presenten una gramàtica pedagògica totalment en la línia de la noció de gramàtica pedagògica desenvolupada per Cuenca (1992). Segons aquesta autora, la gramàtica pedagògica és aquella gramàtica que ha de servir de suport a l'ensenyament i l'aprenentatge de l'ús de la llengua en el context escolar. Per tant, es tracta d'una gramàtica supeditada a l'ús, l'objectiu principal de la qual és la reflexió sobre els coneixements de contingut i procediment implicats en l'ús de la llengua.

Com a gramàtica supeditada a l'ús, els fets lingüístics han de presentar-se jerarquitzats, de forma que el context pragmàtic i semàntic presideixi la descripció formal, en la línia de Zayas (2006). En aquest marc, donada la tradició escolar, una de les problemàtiques que sorgeix en la configuració de la gramàtica pedagògica és el de l'encaix entre els àmbits del discurs i de l'oració.

La unitat morfosintàctica de l'oració sempre ha rebut molta atenció en l'ensenyament i aprenentatge de les llengües. Tradicionalment, però, el tractament de 
la frase ha fet referència a una noció d'oració com un grup de paraules que s'organitza independentment del context d'ús en què es formalitza una idea. Aquesta noció d'oració només convé a les anomenades oracions tipus o oracions canòniques $\mathrm{i}$ trenca amb la continuitat dels àmbits discursiu i oracional. De forma que, perquè els alumnes construeixin estructures explicatives més ajustades sobre el funcionament de la llengua, el desencadenament de l'activitat de reflexió sobre la llengua en interacció no és suficient. Caldrà també que l'activitat dialògica es basi en uns coneixements rigorosament recontextualitzats a l'àmbit escolar, i no directament seleccionats, traduïts i simplificats de la lingüística.

\section{Metodologia}

La investigació té en l'anàlisi de la interacció verbal la seva principal eina metodològica, doncs es parteix de la idea que: L'anàlisi de la interacció permet accedir al coneixement d'una situació concreta que s'organitza a través del discurs, seguint Ribas i Guasch (2011). També considerem que l'anàlisi de la interacció aporta dades o traces de les reflexions sobre la llengua fetes pels alumnes i d'aquelles que es construeixen en el propi diàleg, en la línia de Mercer (2004).

Els objectius principals de la anàlisi de la interacció entre els escolars i la formadora en la sessió observada són: a) conèixer el concepte de gramàtica pedagògica i d'oració que serveixen de base a la proposta de treball a l'aula sobre la frase des del PIL; b) conèixer fins a quin punt el disseny de la sessió afavoreix la construcció de sabers al voltant de la frase a partir de la reflexió sobre la llengua; c) presentar una proposta d'optimització de la sessió.

\section{L’escola i la sessió de modelització del PIL}

L'escola on es va portar a terme l'observació es troba al sector Nord de la ciutat de Sabadell. Es tracta d'una escola de dues línies d'Educació Infantil i Primària inaugurada els anys setanta arran de la demanda escolar que es produí durant aquella dècada pels forts moviments migratoris d'altres comunitats autònomes a Catalunya. Actualment, els alumnes de l'escola són ja nascuts al municipi, però conserven majoritàriament el castellà com a llengua familiar. 
Arran del programa d'immersió per a la normalització del català dels anys vuitanta, el professorat del centre fa servir el català com a llengua vehicular dels processos instruccionals. L'alumnat, però, no sempre fa servir aquesta llengua en les seves interaccions a l'aula i, molt menys encara, en les seves relacions amb altres companys/es en el temps no lectiu. Aquest fet, juntament amb la recent incorporació d'alumnat de la nova immigració al centre, van provocar que l'escola es plantegés el curs 09-10 la conveniència d'incorporar-se al nou PIL.

Com s'ha avançat, la classe que es va observar i enregistrar amb vídeo l'abril de 2010 era una modelització per part d'una formadora del SIAL en un dels dos grups de 1r de Cicle Inicial (6 anys) sobre com treballar la reflexió metalingüística per a la construcció de significats sobre continguts gramaticals, en el context d'un projecte d'immersió.

Cal destacar que la planificació de les sessions de modelització és comuna a tots/es els formadors/es d'immersió de Catalunya. En aquest cas en concret, i d'acord amb la planificació que es reprodueix en la taula següent, l'objectiu principal de la sessió era que l'alumnat fes ús de procediments de reflexió per a la construcció de significats al voltant de la frase:

Taula 1. Planificació de la sessió.

\section{Objectius:}

- Iniciar l'alumnat en els procediments implicats en la reflexió sobre l'estructura d'una frase: reconèixer, identificar, comparar...

- Reconèixer alguns elements que formen part de la frase.

- Comparar elements d'una frase.

- Completar frases.

- Memoritzar la frase.

- Reflexió sobre alguns elements de la frase.

\section{Continguts:}

- La frase.

- Els components de la frase.

- Les paraules.

La sessió es va desenvolupar en tres parts bàsiques: una primera dirigida per la formadora en què es dialoga i es reflexiona en gran grup sobre el concepte de frase i els seus components i es construeixen algunes frases col-lectivament a partir d'un material gràfic. Una segona part, molt més breu, en què l'alumnat treballa en petit grup i construeix oralment i col-lectivament una frase a partir d'un material gràfic, com el que s'ha fet servir prèviament en gran grup, per a després escriure la frase ja individualment en un full. En una tercera part, els alumnes, també de forma 
individual i a mesura que van acabant, mostren a la formadora la frase que han escrit per a la seva revisió. El present article se centrarà principalment en la descripció i l'anàlisi de la primera part, que constitueix el nucli central de la sessió. I més concretament encara, els conceptes de gramàtica pedagògica i d'oració en què es fonamenta $\mathrm{i}$ els coneixements que es construeixen a partir de la reflexió durant la seqüència instruccional, d'acord amb aquests conceptes.

\section{Descripció i anàlisi de la sessió de modelització: La gramàtica pedagògica dels objectius i els continguts proposats i la noció d'oració}

La sintonia de la noció de gramàtica pedagògica de Cuenca (1992) i les presents ordenacions curriculars s'observa principalment en l'organització dels continguts de l'àrea de llengües que gira entorn de tres grans eixos: la dimensió comunicativa, la dimensió literària i la dimensió plurilingüe i intercultural. A la seva vegada, la dimensió comunicativa inclou continguts referits a: a) parlar i conversar, b) escoltar i comprendre, c) llegir i comprendre, d) escriure i e) els coneixements del funcionament de la llengua i del seu aprenentatge. Així, i integrant els coneixements sobre el sistema lingüístic dins del treball de la dimensió comunicativa, queda clar que aquests coneixements i procediments, i la reflexió al seu propòsit, han d'anar dirigits a la millora de l'ús que de la llengua fa l'alumnat.

Una cosa, però, és la gramàtica pedagògica que presenta el currículum i una altra cosa són les pràctiques educatives que es desenvolupen a les aules, moltes vegades contràries a aquesta gramàtica. Aquestes propostes tenen en la seva base les idees del professorat del què és saber i aprendre llengua, i el valor que atribueixen al coneixement del sistema lingüístic, així com també de la seva pròpia experiència com a estudiants i docents, i el pes de la tradició, segons Camps, et al. (2005). Si bé s'entén fins a cert punt que hi hagi diferències entre la gramàtica pedagògica que impregna la present ordenació curricular de Primària (Decret 142/2007) i la que impregna les pràctiques educatives a les aules, resulta poc comprensible que el mateix Departament d'Ensenyament faci propostes educatives que contradiuen en part el nou currículum. Justament aquest és el nostre cas, ja que la pràctica que analitzem és una sessió de modelització dissenyada i planificada pel SIAL, per tal que els formadors/es d'immersió exemplifiquin a les aules d'Infantil i Inicial dels centres 
que formen part del PIL com treballar la reflexió metalingüística per a la construcció de significats al voltant de la frase.

Si s'observen els continguts que apareixen al currículum 142/2007 dins de la subdimensió referida als coneixements del funcionament de la llengua i del seu aprenentatge de Cicle Inicial de Primària, es podrà veure que no apareixen en cap moment continguts referits al treball de la frase. Sí apareixen, entre d'altres, continguts referits a: a) l'observació de les diferències d'ús de la llengua oral i la llengua escrita, a partir dels textos escrits utilitzats a l'aula i b) l'ús de la nomenclatura gramatical que s'està aprenent en català. És a dir, que el treball de la frase, en tot cas i d'acord amb aquesta ordenació curricular, ha de fer-se en el context de l'observació de les diferències entre l'ús de la llengua oral i la llengua escrita.

En canvi, segons l'ordenació curricular 95/1992, els continguts gramaticals que han de ser abordats a Cicle Inicial, i que no estan dins del treball de l'ús i la comunicació de la llengua, són: a) els mots d'una frase i b) els diversos sentits d'una frase oral o escrita amb diferents entonacions o signes de puntuació. El concepte de gramàtica pedagògica que hi ha darrera de la formulació d'aquests continguts del currículum 95/1992, per tant, no és el d'una gramàtica supeditada a l'ús, sinó el d'una gramàtica que té per objectiu el coneixement del sistema lingüístic en si mateix. En els currículums basats en una gramàtica analítica, com el de 1992, es pressuposa que el coneixement explícit del conjunt de regles gramaticals suposa una aplicació automàtica, i, per tant, també una millora automàtica en l'ús, seguint KilcherHagedorn, Othenin-Girard, \& Weck (1987). Fet que, actualment, se sap que no és necessàriament així, com ha posat de relleu Fisher (2004).

Si s'observen els objectius i els continguts que es proposa treballar la formadora en la sessió de modelització relacionats en el punt anterior (taula 1), es veu clarament que aquests no es corresponen amb la gramàtica pedagògica que integra l'actual currículum 142/2007, sinó que estan més aviat en la línia de l'anterior, el 95/1992, en el qual la gramàtica pedagògica i l'analítica pràcticament es correspondrien. Aquest és, sens dubte, un punt feble important de la sessió de modelització.

A més de la gramàtica pedagògica que hi ha a base de la sessió de modelització observada, trobem un altre problema important, conseqüència directe d'aquest primer: la noció de frase de la qual es parteix. Aquesta noció fa referència a 
les oracions tipus o oracions canòniques descrites abans. En la transcripció següent, podem veure com aquesta noció d'oració subjau en les intervencions de la formadora:

Taula 2. Exemple d' intervencions sobre la noció d'oració

\begin{tabular}{|l|l|l|}
\hline 108 & Formadora & $\ldots$ perquè, què hem dit que eren? Què són tot això que tenim aquí ? \\
\hline 109 & Tot l'alumnat & Una frase. \\
\hline 110 & Ivet & Ara una frase, però que té que ser més llarga. \\
\hline 111 & Formadora & $\begin{array}{l}\text { Pot ser més llarga, però sí que és una frase perquè són paraules... quantes } \\
\text { paraules tenim aquí? }\end{array}$ \\
\hline 112 & Tot l'alumnat & Quatre \\
\hline 113 & Formadora & Quatre? Compteu-les! \\
\hline 114 & Tots & Un, dos, tres, quatre. \\
\hline 115 & Formadora & Quatre. I a més a més, aquestes paraules, com les hem posades? \\
\hline 116 & $\begin{array}{l}\text { Alguns } \\
\text { alumnes }\end{array}$ & Com separades \\
\hline 117 & Laia & Ordenades \\
\hline 118 & Formadora & Or... \\
\hline 119 & $\begin{array}{l}\text { Alguns } \\
\text { alumnes }\end{array}$ & Unes separades \\
\hline 120 & Laia & Ordenades \\
\hline 121 & Formadora & $\begin{array}{l}\text { Ordenades, oi? Perquè si no, hem vist que la frase....què ens passava? que no } \\
\text { s'entenia, oi? }\end{array}$ \\
\hline
\end{tabular}

Si bé aquesta noció de frase és molt extensa i compartida en l'àmbit de l'ensenyament de les llengües, el cert és que remet a un metallenguatge col-loquial i força problemàtic, segons Guasch (2010). Una noció de frase fonamentada en una combinació poc rigorosa de criteris formals i semàntics que no pot donar compte de forma ajustada de tots els fenòmens derivats dels usos de la llengua escrits i, molt menys encara, orals.

\section{Els coneixements que es construeixen a partir de la reflexió durant la seqüència instruccional}

Després que la formadora d'immersió que, com s'ha dit, en aquesta sessió condueix la classe per modelitzar, i que els alumnes es presentin, s'inicia la seqüència instruccional pròpiament dita.

La seqüència comença, sense més preàmbuls, $a m b$ un diàleg en què la formadora incita els alumnes en torns successius a recuperar les idees que tenen sobre què és una frase, tal i com es pot veure en la transcripció que segueix:

Taula 3. Exemple d'intervencions a l'inici de la seqüència sense cap context discursiu

\begin{tabular}{|l|l|l|}
\hline 001 & Formadora & Sabeu de què és l'activitat que farem avui? \\
\hline 002 & Tot l'alumnat & Nooo! \\
\hline 003 & Formadora & $\begin{array}{l}\text { No? Doncs...mira, mira què porto aquí, mira, mira, mira... (ensenyant un } \\
\text { material gràfic que utilitzaran més tard per a construir frases col·lectivament) }\end{array}$ \\
\hline 004 & Tot l'alumnat & Oaala! \\
\hline 005 & Formadora & Doncs...sabeu per què ens servirà això? \\
\hline 006 & Tot l'alumnat & Nooo! \\
\hline
\end{tabular}




\begin{tabular}{|l|l|l|}
\hline 007 & Formadora & Ens servirà per fer una activitat. Hmmm, Roger, saps per què ens servirà això? \\
\hline 008 & Roger & No \\
\hline 009 & Formadora & No? \\
\hline 010 & Joana & Per fer l'activitat \\
\hline 011 & Formadora & Per fer l'activitat sobre la frase. Sabeu què és la frase? \\
\hline 012 & Tot l'alumnat & Sí!! \\
\hline 013 & Formadora & A veure! \\
\hline 014 & Roger & La paraula. \\
\hline 015 & Formadora & $\begin{array}{l}\text { Qui ho sàpiga que aixequi el braç. Jo us ho pregunto, vale? Jordi, què és una } \\
\text { frase? }\end{array}$ \\
\hline
\end{tabular}

En relació amb aquest inici, com en el de qualsevol seqüència d'ensenyament i aprenentatge, estem d'acord que és important partir dels coneixements previs de l'alumnat. Però és molt qüestionable que el treball s'iniciï sense que es faciliti als alumnes cap context discursiu en què ancorar les seves reflexions. Tanmateix, aquesta manca de context no només es dóna en un moment introductori de la sessió, sinó que també es dóna en el moment del seu desenvolupament central. Un context que, des del nostre punt de vista, hauria d'haver estat un text escrit, com ara un conte o una narració breu. Si la molt discutida noció d'oració té operativitat, no hi ha dubte que és en l'ús escrit, com a unitat morfosintàctica màxima que ajuda a organitzar el text. D'aquesta manera, per tant, l'espai on situar la reflexió al voltant de la frase, d'acord amb l'ordenació curricular de Primària 142/2007, hauria d'haver estat la comparació entre els usos orals i els escrits, entre un mateix conte (o narració breu) narrat $\mathrm{i}$ escrit, per exemple. En aquest espai els alumnes haurien pogut observar que en els usos escrits el discurs es codifica a partir d'oracions i reflexionar de forma explícita i específica sobre per què i com es fa aquesta codificació. Curiosament els qui en les seves propostes de definició del concepte de frase fan referència explícita als criteris gràfics que ens serveixen per reconèixer-les en els usos escrits són els alumnes. En les seves intervencions, s'observa que situen la noció de frase en l'àmbit escrit, quelcom que la formadora no aprofita per fer el treball que proposàvem:

Taula 4. Exemple d'intervencions dels alumnes que situen la frase en l'àmbit escrit

\begin{tabular}{|l|l|l|}
\hline 019 & Formadora & Doncs, podria ser...Què més? Laia? \\
\hline 020 & Laia & Ummm...és una cosa que...que diu si...si la tens que llegir "entera" \\
\hline 021 & Formadora & Per tant, és una cosa petita i que la llegeixis sencera \\
\hline 022 & Ivet & "Hasta" el puntet. "Hasta" el puntet \\
\hline 023 & Formadora & $\begin{array}{l}\text { Fins a un puntet, bé! Fins a un punt...Però, aquesta cosa, aquesta cosa que ens } \\
\text { diu la Laia, què és aquesta cosa, Ivet? }\end{array}$ \\
\hline 024 & Ivet & És una frase que posem moltes "palabres" \\
\hline 025 & Formadora & Posem moltes paraules \\
\hline 026 & Ivet & $\begin{array}{l}\text { I "después" posem un punt, i després la corregim, i si està malament la tenim } \\
\text { que posar. }\end{array}$ \\
\hline
\end{tabular}


027 Formadora $\quad$ Molt bé! Sabem que una frase són paraules, heu dit, oi? A veure, qui em sap dir una frase? Qui em pot dir una, de frase? Digues, Joana!

L'activitat central, dirigida per la mestra, consisteix en la formulació col·lectiva oral de frases en gran grup, a partir d'una sèrie de quatre imatges que respon a una estructura de frase de subjecte (ex. el gat) + verb (ex. caça) + complement directe (ex. un ratolí) + complement de lloc (ex. a la cuina), per a després escriure-les a la pissarra (act.1). En un primer moment d'aquesta activitat (act.1.1.), la formadora presenta i enganxa a la pissarra les imatges una a una, ordenades d'acord amb l'estructura esmentada, i, cada cop que es presenta una imatge, es demana a l'alumnat que oralitzi la part de la frase que es correspondria amb la imatge. Quan han oralitzat la frase completa, els nens i les nenes l'escriuen a la pissarra fent correspondre igualment el que escriuen amb les imatges.

En un segon moment d'aquesta activitat (act.1.2.), la formadora presenta als alumnes les imatges de forma desordenada i demana a un petit grup d'alumnes que les ordenin. Després els fa oralitzar la frase per parts i, quan ja la tenen construïda, enganxen les imatges a la pissarra $\mathrm{i}$ escriuen la frase a la pissarra, com abans, fent correspondre el que escriuen amb les imatges. Per ajudar-los, la formadora fa coincidir la presentació de cadascuna de les imatges, a les preguntes: qui?, què fa?, què "verb corresponent en $3 a$ persona del present d'indicatiu"?, i on "verb corresponent en $3 \mathrm{a}$ persona del present d'indicatiu"? No hi ha dubte que aquestes ajudes, malgrat que tenen una intenció organitzadora, són gramaticalment poc rigoroses $\mathrm{i}$ indueixen a l'alumnat, per exemple, a identificar el subjecte de la frase amb el paper semàntic d'agent.

En aquesta activitat ja no només no hi ha un text que faciliti uns paràmetres discursius, sinó que es fa un treball de manipulació dels components d'una frase sense tenir el context de la frase completa al darrera. Si utilitzem els dos nivells complementaris d'anàlisi següents: 1) el de la frase com a unitat morfosintàctica i 2) el nivell del text com a unitat discursiva, en aquesta activitat no hi ha ni context morfosintàctic ni context discursiu, de manera que es produeix una doble manca de context. Segons el nostre parer, hauria estat millor abordar la construcció oral i col·lectiva de frases presentant la seqüència d'imatges a la inversa 0 , com a mínim, presentant la imatge que la formadora mostra com a l'última just la primera. És a dir, partir del tot, de la idea, per anar després, i en tot cas, a les parts. Aquesta manca 
doble de context fa que molts alumnes no entenguin exactament què s'espera d'ells en aquesta activitat central i que sorgeixin algunes dificultats. Aquestes dificultats estan relacionades amb: 1) Falta d'ajustament de la frase formulada a l'esperada: Els alumnes, com que no coneixen quina és la idea final que s'espera que siguin capaços de formular, algunes vegades ja formulen una frase sencera abans que se'ls mostri tota la seqüència d'imatges, si amb la imatge o imatges presentades fins el moment, ja se'ls acut una frase. D'altres vegades, formulen la frase per parts i a mesura que se'ls presenten les imatges, tal i com demana la formadora, però sovint no diuen el que la formadora espera que diguin. Això succeeix especialment quan se'ls mostra la segona de les imatges, la que correspon al verb. La il·lustració de l'acció de les imatges és interpretada pels nens i nenes de forma diferent, el que fa que no puguin avançar en la construcció oral de la frase fins que aquesta qüestió no es resol. Que això suposi un encallament, quan el que formulen és efectivament una frase, és quelcom que els alumnes no entenen.

2) Formulació de diferents frases per a una mateixa seqüència d'imatges: La manca de context també fa que no tots els nens i les nenes entenguin la seqüència d'imatges com a integrants d'un tot, d'una mateixa idea formulada en parts, sinó com a imatges aillades que il·lustren idees diferents, relacionades amb un mateix centre d'interès. Així, alguns alumnes per a cadascuna de les imatges de la seqüència formulen una frase diferent.

3) Falta d'ajustament de l'estructura de la frase formulada a la demanada: Les frases que oralment i col-lectivament construeix l'alumnat de vegades no segueix l'estructura subjecte + verb + complement directe + complement de lloc que demana la formadora. La manca de context dificulta que els nens i nenes puguin descobrir la correspondència entre la sèrie d'imatges i l'esmentada estructura de frase. Presentant la seqüència d'imatges en l'ordre invers, com proposàvem, això s'hauria evitat.

A continuació, transcrivim un fragment de la sessió que illlustra problemes derivats de la falta d'ajustament de la frase formulada a l'esperada, a causa del desconeixement de la idea final que han de formular:

Taula 5. Exemple dels problemes derivats de la manca de context morfosintàctic i discursiu

\begin{tabular}{|l|l|l|}
\hline 243 & Formadora & Perfecte! Què fa aquest gat? (ensenya la imatge 2) \\
\hline 244 & Pere & Es menja... \\
\hline 245 & Andrea & Esgarrapa \\
\hline 246 & Formadora & Esgarrapa. Molt bé! Esgarrapa. Què més pot fer aquest gat? \\
\hline 247 & Tots & (parlen entre ells) \\
\hline
\end{tabular}




\begin{tabular}{|l|l|l|}
\hline 248 & Marc & Córrer \\
\hline 249 & Formadora & Fixeu-vos en la mà. \\
\hline 250 & Tots & (parlen entre ells) \\
\hline 251 & Formadora & Es... \\
\hline 252 & Alguns & (no comprensible) \\
\hline 253 & Formadora & $\begin{array}{l}\text { Es...molt bé! Mira que ho ha dit bé! Mira que ho ha dit bé! Ella ha dit } \\
\text { "aranyar" i ell ha dit "esgarrapar", oi? }\end{array}$ \\
\hline 254 & Xavi & Sí \\
\hline 255 & Formadora & Digues "esgarrapar" \\
\hline 256 & Xavi & Esgarrapar \\
\hline 257 & Formadora & $\begin{array}{l}\text { Exacte. Podria ser que aquest gat esgarrapés. I si està així (fa el gest } \\
\text { d'esgarrapar), que va fent així (segueix fent el gest). Quina altra cosa podria } \\
\text { estar fent aquest gat? }\end{array}$ \\
\hline 258 & Nens & (parlen entre ells) \\
\hline 259 & Formadora & Ahh! Què vol fer? \\
\hline 260 & Oriol & Atrapar un ratolí \\
\hline 261 & Formadora & Ahh! Pot atrapar...un ratolí. Per tant, podríem dir que aquest gat caça? \\
\hline 262 & Tots & Síii... \\
\hline
\end{tabular}

Després d'aquesta activitat central de construcció oral i col·lectiva de frases a partir d'imatges, es demana als alumnes que facin el mateix en petits grups per a la consolidació d'allò treballat, a partir de seqüències d'imatges diverses que la formadora reparteix als grups (act.2): que primer construeixin oralment i col·lectivament la frase i que després, i un cop construïda, l'escriguin en un full. En aquests moments, es reprodueixen les dificultats derivades de la manca de context i la conseqüent comprensió poc ajustada de la tasca per part de l'alumnat que s'acaben d'explicar, motiu pel qual no ens hi estendrem.

Només cal apuntar que aquestes dificultats provoquen que els nens i les nenes acabin treballant individualment, després de: a) haver-se repartit les imatges entre ells (els grups d'alumnes en la seva majoria són de quatre) aleatòriament, per tal que, a partir d'aquí, cadascú construeixi la frase que li sembla partint de la imatge o b) haver deixat les quatre imatges sobre la taula i al centre, per tal que cadascú, a partir d'aquí, construeixi la frase que li sembli. Cal destacar que en alguns dels grups que opten per aquesta solució la seqüència d'imatges es col·loca ordenada d'acord amb l'estructura i l'ordre treballats abans, i en d'altres no. Les dificultats sorgides en la segona part de la sessió, i que deriven en el fet que l'alumnat acabi treballant individualment i no en petit grup, fa que la tercera part, la de la revisió i tancament de l'activitat (act.3), es limiti a breus intercanvis individuals formadora- alumne/a. Si l'activitat en petits grups s'hagués fet realment en grup, la revisió també s'hauria pogut abordar de forma 
grupal, cosa que sens dubte hauria servit per acabar de fixar els aprenentatges efectuats en la sessió.

Per tot el que hem explicat, s'ha mostrat que en la sessió observada no preval una perspectiva enunciativa i semàntica, d'acord amb una gramàtica pedagògica supeditada als usos lingüístics i a l'ensenyament i l'aprenentatge d'aquests usos.

\section{Proposta d'optimització de la sessió de modelització}

Per a l'optimització d'aquesta sessió de modelització faríem una sèrie de propostes bàsiques, que es podrien fer extensibles a altres sessions de modelització que els formadors/es d'immersió porten a terme als centres, en el marc del PIL. A continuació, expliquem breument la nostra proposta d'optimització. Primer, la gramàtica pedagògica de les propostes que, des del PIL, es proposen desenvolupar a les aules ha de basar-se en una gramàtica pedagògica supeditada a l'ús, com la que integra l'actual ordenació curricular 142/2007, l'objectiu principal de la qual és la reflexió sobre els coneixements de contingut i procediment implicats en l'ús de la llengua. Segon, els continguts i les activitats que, en el context del PIL, es proposen per treballar a les aules al voltant dels coneixements del funcionament de la llengua i del seu aprenentatge, i la reflexió al seu propòsit, han de basar-se en els continguts de l'actual ordenació curricular. En aquesta ordenació en cap pas es planteja a Cicle Inicial el treball de la frase i els seus components, sinó l'observació de les diferències d'ús de la llengua oral i la llengua escrita i l'ús de la nomenclatura gramatical que s'està aprenent. Per tant, és en aquest marc on hauria de situar-se el treball de la frase.

Tercer, la noció de frase a utilitzar en l'observació de les diferències d'ús de la llengua oral i la llengua escrita ha de ser una noció de frase que situï els fenòmens oracionals en el context del textual i discursiu, d'acord amb Guasch (2010). Quart, les propostes educatives del SIAL haurien de sustentar-se en un model sòlid que dotés de coherència totes les propostes per reflexionar i aprendre sobre continguts gramaticals a les aules, a mode de macro-context. Si els nivells d'anàlisi utilitzats anteriorment fan referència tant al context de la frase com a unitat morfosintàctica $\mathrm{i}$ al context del text com a unitat discursiva, el nivell macro es correspon amb el context teòric $\mathrm{i}$ pràctic d'ensenyament de la gramàtica. Un context que serveix de base a les propostes d'activitats d'aula i garanteix la connexió i la continuïtat entre aquestes propostes i l'ordenació curricular actual. 
Des del nostre punt de vista, el model més consistent per servir de suport a les propostes del SIAL, seria una versió del model de Seqüències Didàctiques per aprendre Gramàtica (a partir d'ara, SDG) de Camps (2006), adaptada a les particularitats dels nens i nenes de cicle inicial. El SDG de Camps és un model d'intervenció que proposa abordar els aprenentatges gramaticals a les aules a partir de l'encaix de dues tasques bàsiques: una de recerca i una altra d'aprenentatge. Així, els objectius de les seqüències també són dobles: uns primers estan relacionats amb descobrir el funcionament de la llengua en algun aspecte, $i$ uns segons, inserits en els primers, estan relacionats amb l'aprenentatge d'uns continguts gramaticals específics. Aquestes dues tasques de recerca i aprenentatge, a més, en aquest model es proposen fer a partir de la comprensió i la producció de textos.

Igualment, el model, que planteja desenvolupar els processos instruccionals en tres fases fonamentals - definició de la tasca, desenvolupament de la tasca i informe i avaluació- fa de l'activitat dialògica que es dóna en interacció l'eina principal d'ensenyament $\mathrm{i}$ aprenentatge, perquè proposa com a estructura de treball bàsica el treball amb agrupacions diverses d'alumnat. Per tant, el model permetria continuar fent de l'activitat dialògica la interfície fonamental en què se situa la reflexió metalingüística i l'ús d'un metallenguatge específic, com succeeix a la sessió de modelització observada i analitzada.

No menys important és que la intencionalitat que hi ha al darrere de descobrir el funcionament de la llengua en algun aspecte concret dota de significat per a l'alumnat la tasca de recerca, així com l'aprenentatge dels coneixements i els procediments específics que es necessiten per desenvolupar amb èxit la recerca. Una significativitat que no podia tenir la sessió de modelització observada i analitzada per la seva descontextualització.

Cinquè, tot i que les formadores només modelitzin una sessió a les aules, caldria que la proposta educativa que des del SIAL es fa als centres que formen part del PIL es referís a una unitat o seqüència didàctica completa, basada en un model teòric i pràctic per a l'ensenyament i l'aprenentatge de continguts gramaticals a les aules com el que acabem de proposar. Això facilitaria que el treball a les aules estigués sempre degudament contextualizat i afavoriria que els fenòmens oracionals es poguessin tractar en el marc del textual i discursiu. 
Sisè, les activitats de manipulació dels elements que componen una frase, en el context del treball d'observació de les diferències d'ús de la llengua oral i la llengua escrita, no poden perdre la perspectiva de la frase com a unitat morfosintàctica per molt petit i concret que sigui el nivell d'anàlisi, com succeïa a la sessió de modelització observada. És més, les activitats de manipulació dels elements que componen la frase no tan sols no hauran de perdre una perspectiva morfosintàctica, sinó que tampoc hauran de perdre una perspectiva textual i enunciativa, com ja hem dit.

\section{Conclusions}

La proposta de sessió de modelització del PIL analitzada en aquest article parteix de la base que és necessari l'abordatge de continguts gramaticals a l'aula des de ben a l'inici de Primària. Es fonamenta també en què, perquè hi hagi aprenentatge d'aquest tipus de sabers, caldrà desplegar una activitat de reflexió sobre la llengua a l'aula. Així com que la construcció de coneixements haurà de fer-se a partir de la participació conjunta de docent i alumnes en el discurs, d'acord amb una perspectiva sociocultural.

Estem d'acord amb aquestes idees i considerem que no només són vàlides en el marc de programes que pretenen millorar els usos comunicatius en català, com el PIL, sinó que també ho són per a totes aquelles escoles que es plantegin l'educació lingüística en el primer cicle. Ara bé, amb l'objectiu que aquestes tres idees força aconsegueixin promoure processos d'ensenyament i aprenentatge efectius, caldrà revisar una sèrie d'aspectes, com s'ha apuntat al llarg de l'article. En primer lloc, serà essencial que les sessions de tractament de nocions gramaticals responguin a una gramàtica pedagògica orientada a la millora dels usos de la llengua per part de l'alumnat. De manera que els continguts i les activitats específics que se seleccionin i es dissenyin amb aquest fi s'abordin de forma contextualitzada. És a dir, sense perdre la perspectiva enunciativa $\mathrm{i}$ textual, com hem vist que succeïa a la pràctica en la sessió analitzada. Alhora que, i en segon lloc, qualsevol sessió de gramàtica a l'aula s'haurà de situar en el context d'unitats o seqüències didàctiques completes que les dotin de sentit, coherència i continuïtat. Unes unitats que serà important que tinguin un marc teòric i pràctic al darrera, com el model d'intervenció de SDG de Camps 
(2006). En tercer lloc, caldrà fer una transposició didàctica dels coneixements de la lingüística en l'àmbit escolar que permeti als alumnes construir estructures explicatives ajustades al voltant del funcionament de la llengua i el seu ús a partir de la reflexió. Si es tenen en compte aquests aspectes estem segurs que l'activitat de reflexió sobre la llengua pot ser un instrument de gran potencialitat per a la millora dels usos lingüístics i les decisions que sobre aquests usos prenen els alumnes de Cicle Inicial.

\section{Bibliografia}

Camps, A., \& Milian, M. (2000). Del texto intentado al texto escrito: formulación oral y reformulaciones del texto en el proceso de redacción en grupo, dins: Simposio Internacional de Análisis del Discurso (pp. 2751-276). Madrid: Universidad Complutense de Madrid/ Universidad París XIII.

Camps, A., Guasch, O., Milian, M., i Ribas, T. (coords.) (2005). Bases per a l'ensenyament de la gramàtica. Barcelona : Graó.

Camps, A. (2006). Seqüències didàctiques per aprendre gramàtica. Dins A. Camps, i F. Zayas, (coords.) Seqüències didàctiques per aprendre gramàtica (pp. 3136). Barcelona: Graó.

Cuenca, M.J. (1992). Teories gramaticals i ensenyament de llengües. València: Tandem ediciones.

Decret 95/1992, de 28 d'abril, pel qual s'estableix l'ordenació curricular de l'educació primària.

Decret 142/2007, de 26 de juny, pel qual s'estableix l'ordenació dels ensenyaments de l'educació primària.

Decret 143/2007, de 26 de juny, pel qual s'estableix l'ordenació dels ensenyaments de l'educació secundària.

Fisher, C. (2004). La place des représentations des apprenants en didactique de la grammaire. Dins C. Vargas (dir.) Langue et études de la langue. Approches linguistiques et didactiques (pp.383-393). Aix-en-Provence: Publications de l'Université de Provence.

Guasch, O. (2010). La noción de oración en libros de texto en catalán y en castellano. Dins T. Ribas (Coord.) Libros de texto y enseñanza de la gramática (pp. 7795). Barcelona: Graó.

Kilcher-Hagedorn, H., Othenin-Girard, C., \& Weck, G. (1987). Le savoir grammatical des élèves. Berne: Peter Lang.

Mercer (2004). Sociocultural discourse analysis: analysing classroom talk as a social mode of thinking. Dins: Journal of Applied Linguistics (pp.137-168), Vol 1, $\mathrm{N}^{\mathrm{o}} 2$ (2004).

Ribas, T., \& Guasch, O. (2011), “Análisis de la interacción verbal para el aprendizaje de la lengua: reflexiones metodológicas", dins: Papers de treball del GREAL, 9. Document de treball no publicat. 
Vygotsky, L. S. (1978). Mind in society: The development of higher psychological processes. Cambridge, MA: Harvard University Press. (Original work published in 1960).

Zayas, F. (2006). Cap a una gramàtica pedagògica. Dins A. Camps, i F. Zayas, (coords.) Seqüències didàctiques per aprendre gramàtica (pp. 17-30). Barcelona: Graó.

\footnotetext{
${ }^{1}$ El SIAL utilitza en tot moment el terme "frase" referint-se a les oracions anomenades "tipus" o "canòniques".

${ }^{2}$ Al llarg d'aquest treball, farem servir els termes "frase" i “oració" com a sinònims, d'acord amb la utilització generalitzada d'aquests termes en el context escolar.
}

Agraïments: Agraeixo a Oriol Guasch l'orientació d'aquest treball. També agraeixo al SIAL i al seu equip de formació la seva col·laboració.

\section{Referència de l'autora:}

Anna Méndez i Navarro té el títol de Màster d'Investigació en Didàctica de la Llengua i la Literatura per la Universitat Autònoma de Barcelona. Compagina la seva tasca com psicopedagoga en l'EAP B44 de Cerdanyola del Vallès amb la docència al Departament de Didàctica de la Llengua i la Literatura de la Universitat Autònoma de Barcelona com a professora associada. Actualment inicia la seva tesis doctoral en la línia dels estudis sobre la capacitat de reflexió de la llengua de les persones plurilingües, sota la direcció del Dr. Oriol Guasch Boyé i la Dra. Rosa Gil Juan.

\section{Email: amendez3@xtec.cat}

Per citar aquest article:

Méndez i Navarro, A. (2012). Ensenyar i aprendre coneixements gramaticals al voltant de la frase: Una experiència a cicle inicial. Bellaterra Journal of Teaching \& Learning Language \& Literature, 5(2), 64-81. 